\title{
DIGITAL TWIN: A HBIM-BASED METHODOLOGY TO SUPPORT PREVENTIVE CONSERVATION OF HISTORIC ASSETS THROUGH HERITAGE SIGNIFICANCE AWARENESS
}

\author{
P. Jouan ${ }^{1, *}$, P. Hallot ${ }^{1}$ \\ ${ }^{1}$ Dept. of Architecture, Art Archaeology and Heritage Research Unit, LNA-DIVA, Université de Liège, Boulevard de la constitution, \\ Liège, Belgium - (pjouan, p.hallot)@uliege.be
}

Commission II, WG II/8

KEYWORDS: Historic Building Information Modeling (HBIM), Digital Twin (DT), Heritage documentation, preventive conservation.

\begin{abstract}
:
During preliminary phases of conservation projects, a considerable amount of heterogeneous datasets are produced, gathered, analysed and interpreted. Abundant researches have gradually proven that Historic Building Information Modelling (HBIM) is a relevant alternative for the collaborative management of information related to existing structures. Apart from the obvious benefits of HBIM for information exchange among stakeholders during conservation project, the potential of such processes to support preservation strategies should not be neglected. Moreover, the recent developments of HBIM web-interfaces illustrate the need for additional investigation in strengthening the relationships between the digital model and the real-world to better support preventive conservation of heritage places. Besides, values-based approaches for the elaboration of conservation strategies have been gradually adopted in the last decades, both in academic and professional sector. In this paper, we propose a comprehensive methodology to structure and integrate the cultural significance of tangible and intangible elements into HBIM models to be further taken into account in the analysis and simulation of data. This article suggests the application of Digital Twin (DT) principles to support site managers in the preventive conservation of their assets. Based on the analysis and simulations of data captured by onsite sensors, threats to the site integrity and corresponding preventive solution can be predicted in the DT environment. The integration and structuration of Heritage Values in HBIM models allow further evaluation process to estimate the impact of each suggested interventions on the conservation of features of significance.
\end{abstract}

\section{INTRODUCTION}

In the field of Cultural Heritage $(\mathrm{CH})$ documentation, the technological improvements accomplished during the last decade(s) resulted in an increased variety and complexity of information sources (Van Balen, 2017). The possibilities offered by today's tools and workflows for digital representation and information management open new perspectives in term of Data acquisition (Terrestrial Laser Scanning (TLS), Aerial \& Terrestrial Photogrammetry, Electronic Distance Measurement (EDM), etc.), data structuration (Computer Aided Design (CAD), Building Information Modeling (BIM), GIS (Geographic Information System), etc.), and data dissemination.

The application of BIM principles to existing structures is made possible through the acquisition of high-quality point clouds obtained through TLS or photogrammetric surveys. On this basis, a digital model representing accurately buildings' present condition can be achieved and later on be used in a platform for collaborative data management. Up to a lot of researches focusing on Historic Building Information Modeling over the last decade, the ability of such process to meet the requirements of Heritage Conservation stakeholders in terms of data management has been widely investigated. Even though these studies highlighted numerous benefits of adopting HBIM in $\mathrm{CH}$ framework, several issues still need to be discussed to fully address the very specific and complex needs of heritage preservation's professionals. While issues related to the level of detail and accuracy of the digital 3D reconstruction of nonregular geometries has attracted the attention of most researchers, very few got interested either in integrating the notion of heritage significance in the data models or lesser in the spatiotemporal evolution of represented information within HBIM process and its implication.

"Conservation of cultural heritage in all its forms and historical periods is rooted in the values attributed to the heritage" (ICOMOS, 1994)

As established in the Nara Document on Authenticity, the understanding and definition of sites' heritage values are prior to the establishment of any conservation strategy aiming at preserving their authenticity and ensuring their integrity (Fredheim and Khalaf, 2016; Van Balen, 2008). However, several issues hinder the consideration of preliminary studies' results in further phases of heritage assets lifecycle (design, construction, operation, and management, etc.). More particularly, as highlighted in a research conducted in the GICARUS lab, at the "Politecnico di Milano" (Brumana et al., 2019), the outputs of initial investigation work, once completed, are often stored in local databases (physical archives, digital databases, etc.). While the initial aim of such valuable documents is to guide stakeholders in defining further actions plan for the conservation of $\mathrm{CH}$ assets, such data decentralisation significantly weakens their actual impact on further decisionmaking processes. That being said, attempts should be made to incorporate this type of data into the digital data management processes.

\footnotetext{
* Corresponding author
} 
Moreover, once the model is achieved, BIM's process mostly relies on end-users and operators to keep the model constantly up to date. This task requires important human and financial resources that are hardly ever available. The risk is then higher for these data models to be rapidly forgotten in local databases. Recent significant developments in sensors technologies, together with the emergence of the Internet of Things (IoT) have made possible the implementation of new supportive tools for the operation and maintenance of buildings. In this framework, the DT concept, originally defined as a "virtual representation of what has been produced" (Grieves and Vickers, 2016) has gradually attracted the attention of the construction sector. A digital copy of the construction connected to knowledge databases as well as sensors providing real-time operational data from the real world permits the automatic detection of potential hazards and execution of suggested possible solutions under the supervision of experts. Combining both BIM and DT principles would ensure the valuable data contained in the static data model to be taken into account when analysing the data received from sensors and would allow estimating how condition changes might affect buildings and sites' components. Endeavours to generate relationships between the data collected by sensing devices, placed in the physical object, and the data stored in HBIM model can already be observed both in the academic and professional sectors, such as the HBIM portal project (HBIM Portal Development Team, 2016) or in PetroBIM (PetroBIM Development Team, 2013) commercial viewer for instance. These projects and initiatives clearly demonstrate the need and interest for further research to allow more interactions between HBIM data models and physical assets aiming at making more efficient the different data management processes.

In this article, a methodology combining HBIM with DT concept and integrating the results of preliminary studies to support the preventive conservation of places with heritage significance is proposed.

\section{BIM FOR CULTURAL HERITAGE}

Originally thought of for new constructions, BIM aims at improving construction sector's competitiveness by significantly reducing constructions' costs and time avoiding a great number of errors during the execution of the works. This multidimensional and collaborative process proposes more efficient management of all the information linked to a site during all its lifecycle. To achieve such goals, a complex digital 3D model composed by smart elements is built at the outset of a project, constantly kept up-to-date, and used as an information exchange platform for all stakeholders (Garagnani et al., 2012).

In the past few years, many researches focusing on BIM's potential to address the needs of Heritage Conservation professionals demonstrated the BIM's applicability in the framework of a conservation project once combined with very detailed records. Actually, the main difference between BIM and HBIM is the conception of the digital model at the inception of the project (Figure 1). While the former implies the design of the entire model from the sketch phase onwards, the latter requires a digital representation of the site's present condition based on a complete and accurate survey, historical research and on-site observations (Barazzetti et al., 2015). A digital library of all building elements constituting the monument is then generated by modeling them in $3 \mathrm{D}$, linking them to any related data and assigning them properties \& attributes. The digital model of HBIM process is further achieved by mapping construction elements on the point cloud.

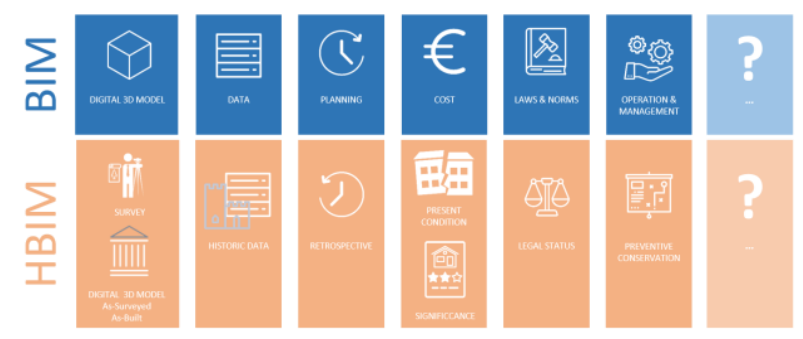

Figure 1 - The figure depicts the type of information that should be integrated in HBIM data model in comparison with standard BIM data models.

As explained earlier, extensive documentation and understanding of assets' present condition are required at the beginning of a conservation project. Once the collected data is structured and integrated into the digital model, the latter can be used in a platform where stakeholders can manage the data on a collaborative basis. Additional datasets will then be progressively integrated along with the different phases of the assets lifecycle (design \& research, construction, management and operation, preservation, etc.) as extra layers to the model in order to keep it up-to-date and always provide a clear understanding of the site's evolution. In case of disappearance of the physical object, the data centralization and structuration of the HBIM model will ensure a very complete digital preservation of all the information linked to the asset for future generations (Figure 2).

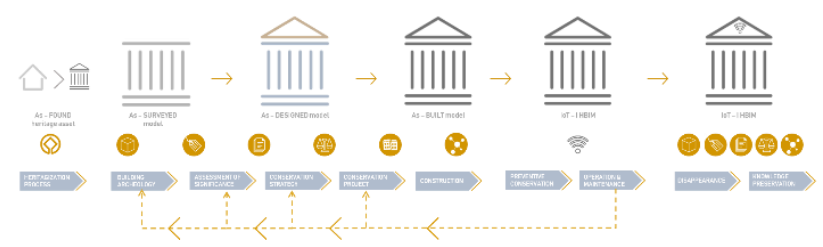

Figure 2 - The scheme illustrates the evolution of the data model in HBIM data management processes along the different phases of Heritage places lifecycle.

Previous investigations have highlighted various possible practical applications of HBIM process during Heritage Conservation project such as:

- HBIM's potential for documentation (Cheng et al., 2015; Garagnani et al., 2012)

- Pathologies analysis, scenarios simulation, Finite Elements Analysis, digital support of conservation plans (Brumana et al., 2017)

Digital representation through Augmented and Virtual reality (AR \& VR) (Barazzetti et al., 2015)

Interoperability with GIS and CityGML (Dore and Murphy, 2012; Isikdag and Zlatanova, 2008).

Apart from the numerous benefits of applying HBIM process for the management of information along with the different phases of a project, highlighted in previous investigations, several issues have also been identified. The most striking is probably the one related to the very complex digital reconstruction of building components having irregular geometries while keeping their properties and attributes as well as their interrelations with the surrounding construction elements. Actually, many researches (Oreni et al., 2017, 2014) have been undertaken to solve the issues and it makes no doubt that software developers will propose appropriate tools for the modelling of existing structures. 
As mentioned earlier, even though it acknowledges the importance of addressing the issues in connection with the accurate $3 \mathrm{D}$ reconstruction of building elements, this article rather focusses on the aspects of HBIM related to the relationships between the physical object and the digital data model and to the integration of cultural significance in HBIM process.

\section{HERITAGE SIGNIFICANCE STATEMENT IN HBIM}

The main goal of HBIM is to improve the efficiency of data management processes among $\mathrm{CH}$ stakeholders to ensure more sensible preservation of historic assets and to reduce the costs linked to conservation works. Despite the significant amount of researches already carried out in the field, very few seem to have integrated the aspect of cultural significance together with the legal status and state of conservation of building elements in HBIM process. Considering the important role they play in the elaboration of conservation and management plans for historic places, the integration of such valuable data in HBIM is of major importance to guarantee their impact on the decision-making process at all stages of historic places' life cycle. Indeed, the understanding and dissemination of the values attached to historic assets are required before providing guidelines for the establishment of conservation and management plan.

According to Chiabrando's research focusing on the modelling of decay in HBIM models (Chiabrando et al., 2017), the integration of information related to the present condition of existing elements in such models does not appear to be an insuperable barrier. On the other hand, importing and structuring the statement of significance into HBIM models is a more challenging issue. Indeed, despite the large amount of values typologies proposed since the publication of the Nara document on authenticity in 1994 (ICOMOS, 1994), no classification model has been universally recognised and adopted in practice. According to a critical reflexion on previous values classification models (Fredheim and Khalaf, 2016), most typologies failed for several reasons such as, for instance, the lack of flexibility to ensure their applicability regardless of the spatial and temporal context. The often very implicit aspect of value assessments also complicates its understanding by heritage conservation professionals and restrict their possible impact on the decisionmaking processes during the elaboration of management and conservation plans. Moreover, significance assessments, as well as the values typology used to perform them, should remain open for future reviewing since they can differ depending on spatial and temporal context.

"Encoding" the cultural significance of tangible and intangible elements as analysable and interpretable data in a rigid HBIM data model is a complicated task since it requires the strict structuration, in a rigid model, of often very complex and elaborated statements. Such an operation involve the use of a values classification methodology which structure could be used as a basis for further data structuration in HBIM models. After a critical analysis of previous values typologies, Fredheim and Khalaf (Fredheim and Khalaf, 2016) presented a new approach which aims to tackle the identified concerns. In their analysis, they distinguished three important phases (Figure 3) in the assessment process that need to be achieved in to ensure the completeness of the evaluation. The assests to be valued are first listed and described. The reasons of there significance are then exposed in a second stage. Finally, the third phase consists of determining how valuable the identified elements are.
Based on Stephenson's Cultural Values Model (Stephenson, 2008) the first stage concerns the identification of both tangible and intangible aspects embodied in a heritage site and their classification in three main categories (forms, relationships, and practices). The goal of this phase is to provide a very clear description of all elements bearing heritage values avoiding any subjectivity. The flexibility of such method ensures its universal character and, accordingly, its adaptability to any spatial or temporal context. In a second phase, after having defined what is being assessed, four aspects of value (associative, sensory, evidentiary and functional) allow determining the reasons why each element of significance is valuable. Finally, they suggest the use of "Qualifiers of value" (Authenticity, rarity, condition) to help to specify how valuable the studied object is. This third phase in their methodology for the elaboration of a statement of significance is essential because it makes the links between the interpretations, judgments, values on the one hand, and how perceivable they are through the observation of the physical object, on the other hand. Taking into account the very complex aspect of value assessment, this step also permits a kind of simplification that provides heritage stakeholders with more "explicit" guidelines for the conservation of their heritage.

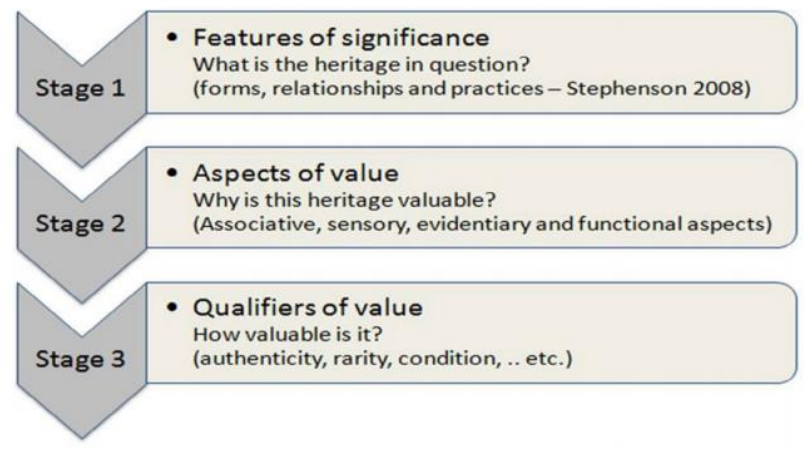

Figure 3 - The three phases of Fredheim \& Khalaf's process for the assessment of Heritage assets' significance (Fredheim and Khalaf, 2016).

Importing the statement of significance in HBIM data model implies first the incorporation of the complete statement of significance to the model as raw data. Then, the structure of Fredheim and Khalaf's values typology can be used as a model for prototyping data structuration in HBIM model. The information can then be organised in categories and subcategories in the HBIM model according to the logic of their values classification's method. For comparison purposes and to ensure the interpretability of such data by the software either in HBIM or in DT environment, a quantitative assessment has to be deducted from the qualitative data introduced. The objectivity of this last crucial step will be optimized thanks to the very logic and structure of the evaluation methodology (What, Why, How?).

Shortly, as mentioned previously, the value assessment is the key connection between the preliminary studies and the following stages of a conservation project (design, construction, operation $\&$ maintenance) and plays a key role in the elaboration of conservation strategies. The statements of significance can only have a meaningful impact on the development of such strategies if they are confronted with other data such as the legal status of Heritage sites and their present condition (pathologies). Considering the latter, efforts should be made to intent including these parameters in HBIM process in order not to disconnect the conclusions of early investigation works and value assessments 
from the following phases of heritage structures lifecycle (design, construction, operation, and management, etc.).

The values typology proposed by Fredheim and Khalaf (Fredheim and Khalaf, 2016) clarifies the process for assessing the significance of Heritage Places. Their workflow's structure could be used as the basis for developing a data structuration model for the integration of such complex documents into HBIM data model. In line with their approach, the structuration of data in HBIM models should allow its universal adaptability and possible further review. Furthermore, the data should be imported and organized in such a way that they can be taken into account for further data analysis and simulations processes. This task has to be performed during the operation and maintenance of heritage sites to support their preventive conservation.

\section{DIGITAL TWIN}

Even though the concept has carried different names, early stages of the "digital twin" idea can be found in the first years of the 21 st century. Indeed, back in 2002, Michael Grieves presented a project for a "Product Lifecycle Management (PLM) centre" (Grieves and Vickers, 2016) where all the basic principles of the DT concept are present. Grieves defined DT as a "virtual representation of what has been produced. Compare a Digital Twin to its engineering design to better understand what was produced versus what was designed, tightening the loop between design and execution"(Grieves, 2014). Initially mostly applied in "astronautics and aerospace area"(Grieves and Vickers, 2016), recent progress in IoT (Internet of Things) infrastructures and in home automation technologies allowing the development of more affordable sensors to capture real-time data from the physical model led to a greater interest in applying DT concept to the construction sector. Implementing DT for the management and preservation of $\mathrm{CH}$ assets requires adopting a collaborative integrated approach meaning the inclusion of specialists in disciplines such as building physics, sensing data collection, electronics \& IoT, in the data management processes.

The interest of using sensors for the preservation of places of significance and on the type of variables that can be monitored will be examined in a first step. Then, the potential of HBIM models to serve as the digital replica in DT process and to connect DT to the very rich data gathered along the lifecycle of historic structures will be questioned.

\subsection{Sensing \& Cultural Heritage:}

Since decades, specialists in $\mathrm{CH}$ preservation use sensing devices to monitor specific factors influencing internal and external conditions of assets to support their preventive conservation (Elfadaly et al., 2018). Based on observation, control, and record of a wide variety of "critical physical parameters, sensors allow scientists to detect abnormal changes in environmental conditions that could threaten buildings and sites' integrity. As mentioned by Moraitou, Aliprantis, \& Caridakis (Moraitou et al., 2018), in addition to the obvious short-term benefits, long-term storage of data provided by the sensors can contribute to a better understanding of interferences between $\mathrm{CH}$ assets and their environment by comparing such data to the information collected along with the different phases of conservation projects.

Sensors can capture and monitor a wide variety of variables affecting buildings and sites environment. Besides the need to analyse parameters related to climate control within and around $\mathrm{CH}$ assets, other categories of sensing devices might attract the attention of Heritage Conservation stakeholders (Klein et al., 2017). As illustrated in a project led by the University of Cordoba (Mesas-Carrascosa et al., 2016), Spain, interior temperature and relative humidity, the external climatic conditions and spaces' occupancy can be monitored in relation to the configuration of the site to better understand their interrelation. The joint analysis of such data can help in identifying issues and potential threats related to the initial design, spatial configuration, occupancy, and understand the process behind to suggest further possible solutions. Apart from the variables linked with climate control, others related to air quality, light radiation, acoustic performances, energy consumption and structural behaviour (crack monitoring, vibrations, etc.) can be observed.

The environmental factors to be monitored on a site should be determined in relation with specific potential hazards and issues identified either by experts in the preliminary studies or directly by users and operators responsible for the operation and management of the asset thanks to their experience and knowledge about the place. Since the very aim of implementing these monitoring tools is to support a more sensible approach of $\mathrm{CH}$ preservation and reduce the costs linked to conservation works, the placement of sensing devices is limited to the minimal amount required for the control of the identified key parameters. The type of sensors to be used as well as their location can then be established. Instead of monitoring the data coming from various sets of sensors separately, the goal is to perform joint analysis and simulation of various parameters to fully identify (potential) deterioration processes and possible causes as well as suggesting interventions to prevent hazards to occur.

\subsection{HBIM model as digital replica}

Since the design phase and all along buildings' lifecycle, the digital replica of a DT can assist stakeholders in the decisionmaking processes through simulations $\&$ analysis thanks to the use of real-time operational data captured by sensors in the physical "world" and constantly updated knowledge databases. Literally, the digital replica used in DT process is a very accurate three-dimensional representation of the physical object. Considering previous reflexions on HBIM models, HBIM data management process and on the need to compare all the information related to $\mathrm{CH}$ assets and gathered along their lifecycle to the data collected by sensing devices in the physical object, adopting the up-to-date HBIM model as the digital replica in DT process seems promising.

DT and HBIM processes can complement one another to propose a very complete and efficient data management process. Indeed, while Building Information Modeling relies mostly on a constant manual update of the model by the users, the DT is directly connected to the real-world object and receives instantly updated operational data with no users' intervention required. One of the major interest of the DT lies in the automation of processes such as, for instance, the analysis of data for potential hazards detection, the research of technical solutions and possible actions to be undertaken and their actual execution. Performing such analysis and simulation while taking into account the data stored in HBIM model can even help buildings' managers evaluating the impact of each suggested technical solution on features of significance. When considering the significant amount of data to be found, gathered, analysed and compared as well as the impossibility for human operators to complete such a task as efficiently as a computer, the automation of the workflows mentioned above will allow site managers to spare resources and take much more factors into account in the decision-making process related to the conservation of their assets. 
The next step is to model a digital workflows prototype to import HBIM models into DT software while conserving the attributes and the structure of the model. To do so, the principles of AGILE method is applied. The prototype will be developed and tested at the same time to directly identify conflicts and search for alternatives. The idea is not to develop new software but rather to make the best use out of existing available ones.

Existing HBIM web platforms seem to already integrate both the data contained in the HBIM model and real-time data coming from sensors generating graphs and figures. For instance, PetroBIM (PetroBIM Development Team, 2013) is an online tool to visualize, add and extract data related to historic sites based on a three-dimensional model. The online viewer also allows the placement of sensors on the digital model, but further investigations need to be conducted to understand how such data can further be analysed and simulated. Similarly, the "HBIM PORTAL" (HBIM Portal Development Team, 2016) project led to the development of an open source web platform that roughly performs the same tasks although the viewer can also handle point clouds files. With this viewer, among other applications, one can navigate in the three-dimensional model, explore the graphs summarizing the data obtained from various sensors and compare them with each other. The development of these tools demonstrates the needs of Heritage stakeholders' for new approaches, taking advantages of new technologies, for the management of all data related to specific assets permitting more interactions between the physical and digital model. Furthermore, the developers of these platforms have started to investigate the feasibility of merging data from HBIM models together with the information collected by sensing devices.

\section{H-BIM \& DIGITAL TWIN METHODOLOGY FOR CULTURAL HERITAGE PRESERVATION}

Taking previous reflexions into account, it is suggested to review data structuration in HBIM model and integrate the very specific aspects of Heritage Conservation such as the heritage significance, legal status and actual condition of assets. The main objective is to bridge the gap between the different phases of an asset's lifecycle as well as ensure and strengthen the impact of preliminary studies in the decision making processes.

We also suggest using the up-to-date as-built model from HBIM process as the digital replica for DT. The real-time data provided by sensing devices placed in the physical object will allow tackling the issue of the static character of HBIM models. Further automated analysis and simulation can be achieved using the data captured by the sensors to detect potential hazards. Beyond their identification, the risk they represent should be estimated taking into consideration the probability for the threats to occur and their possible consequences. Further research is needed for the development of a matrix allowing hazards' risk assessment in a digital twin environment for $\mathrm{CH}$ assets preservation. In addition, several technical solutions can be proposed to solve identified issues and an evaluation process could establish their impact on all aspects that affect the assets' management (including the consequences on the integrity and authenticity of the place as well as on the perceptibility of heritage values for the different features of significance).
Through a web-interface similar to HBIM portal, such a methodology will provide site managers and operators with observations indicating possible threats to the integrity of objects, suggesting preventive actions to undertake to protect them and evaluating the impact of each solution proposed on all aspects (budget, sustainability, heritage significance, legal protection, etc.). Moreover, in the long-term, monitoring and storage of data from sensors could lead to a better understanding of buildings' behaviour and monitor the actual efficiency of the implemented solutions (Figure $4 \& 5$ ).

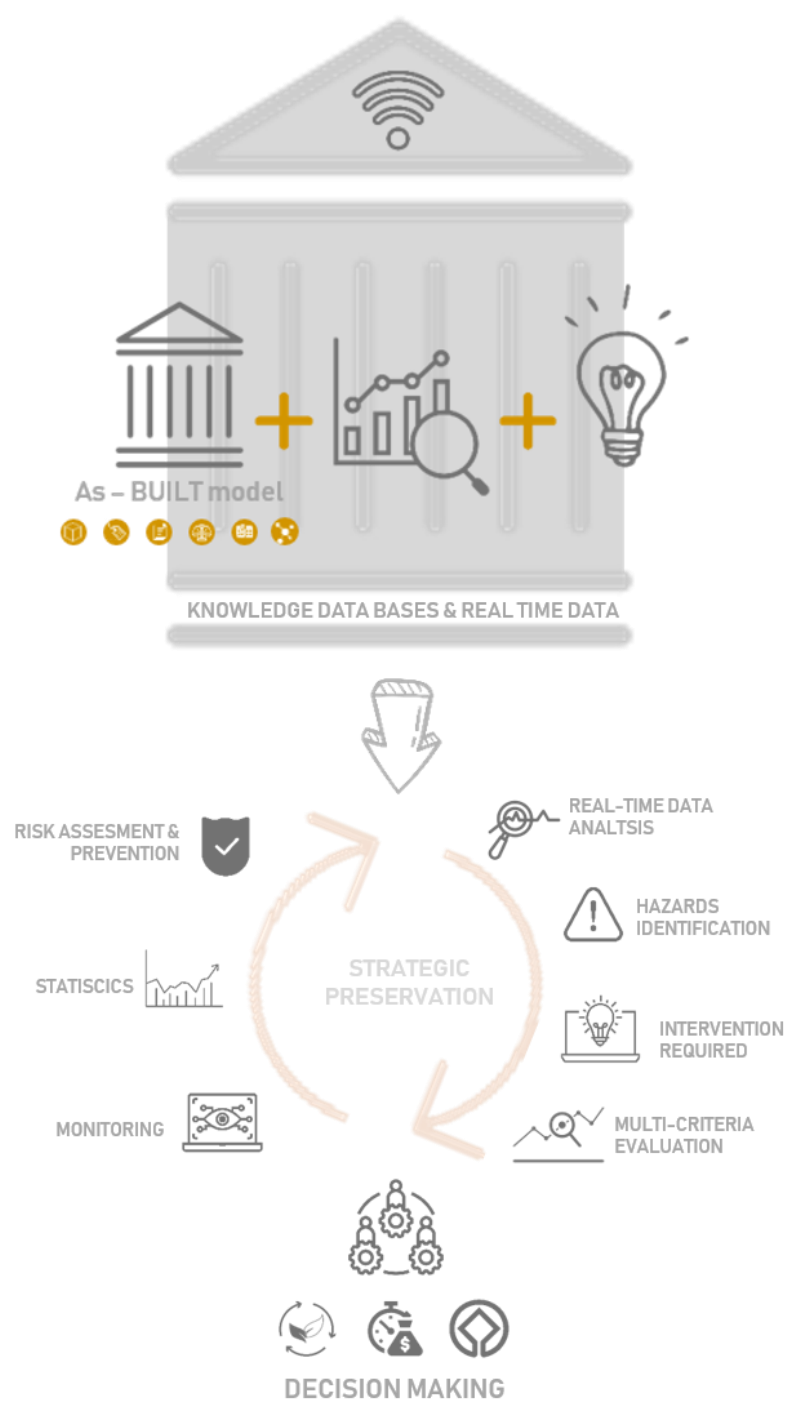

Figure 4 - The scheme shows the general data analysis and simulation workflow in Digital Twin environment, with HBIM model as digital replica, to support decision making processes for the preventive conservation of assets.

Following the principles of AGILE method, the methodology will be developed and tested at the same time on a very specific case study in order to immediately detect problems and adjust the workflow accordingly. This bottom-up process will initially focus on a very and specific case-study and further be adapted for broader application. 


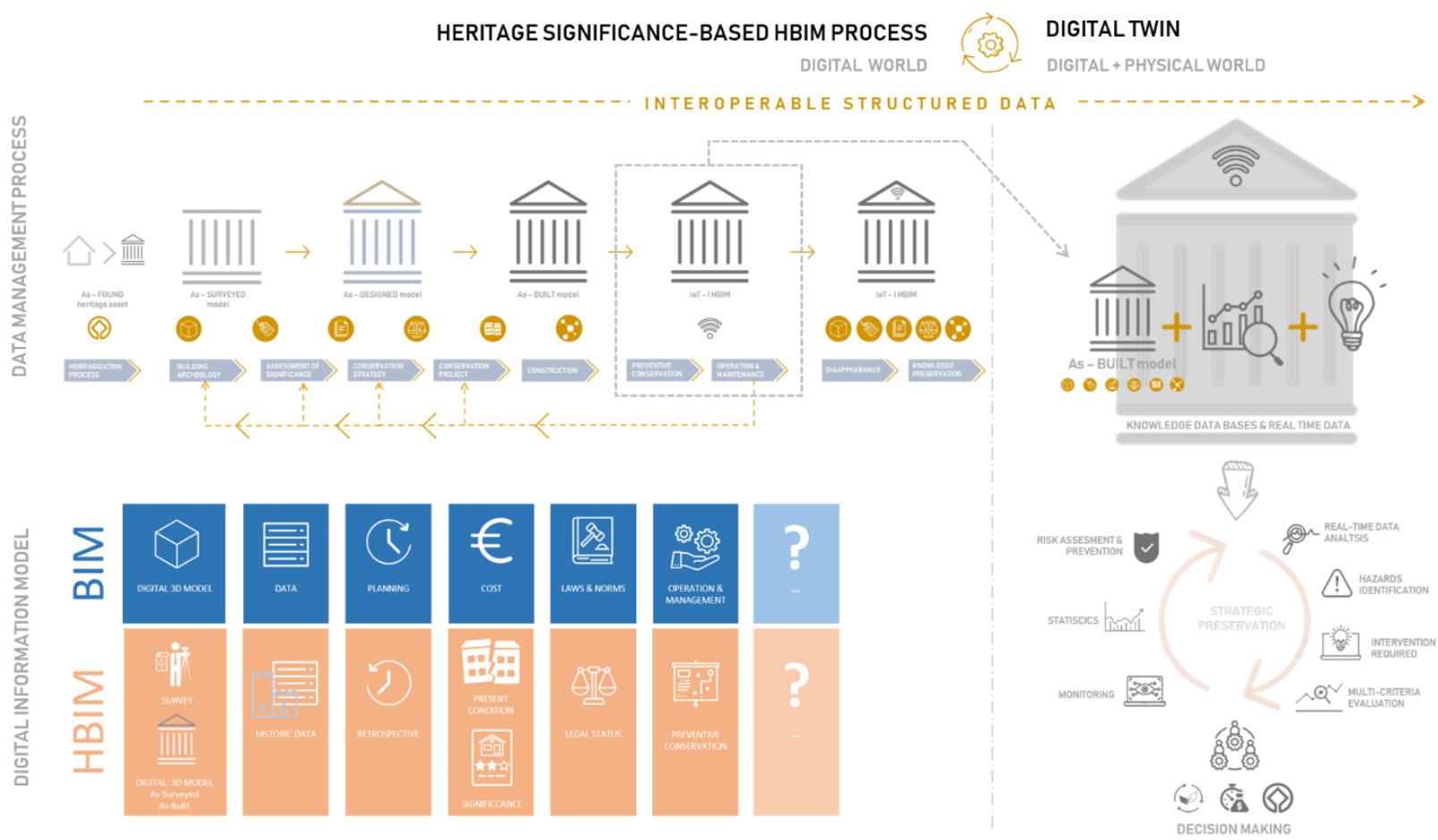

Figure 5-These illustration depict the complete methodology presented in the article and the relationships between the different workflows and concepts. The schematics show data organisation in HBIM model (lower-left corner) and how the latter further evolves along the different phases of historic places lifecycle (upper-left corner). Additionally, the diagrams on the upper-right corner express the relation between the HBIM model and the digital twin on the one hand, and how they are connected to the physical object

through the placement of sensors collecting real-time data. The last scheme (lower-righ corner) describe the main steps in the analysis and simulation processes supporting decision-making processes for the preservation of Heritage assets.

\section{CONCLUSION AND FURTHER RESEARCH}

Based on a literature review, we highlighted the need to investigate the integration of heritage assets' significance in HBIM process and the application of DT concept based on HBIM digital models to propose an alternative and more efficient method for preventive conservation. In this paper, a methodology that integrates these concepts from the documentation process of conservation projects onwards is proposed and can be summarized in three major steps. Further perspectives of research have been identified for each phase.

First of all, a cultural significance-based HBIM model can reinforce the impact of experts' conclusions from preliminary studies on the other phases of a historic assets lifecycle. The centralization of data in HBIM also allows avoiding the dispersal and loss of information that often happens in the case of data stored in local archives or databases. The paper has highlighted that the encoding of data related to the Cultural Significance of assets requires the elaboration of a prototype model for data structuration in HBIM. It has been proposed to use the structure of Fredheim and Khalaf's values typology (Fredheim and Khalaf, 2016) as a reference. One of the major issues is related to the difficulty of transforming qualitative data, inserted in the model, into quantitative data allowing them to be taken into account in the analysis and simulation processes in HBIM and DT environments.

Secondly, the application of DT concept based on a HBIM digital model containing such valuable information could eventually lead to assisted or automatic identification of hazards and technical solutions for a more efficient and wise preventive conservation of heritage assets. Further investigation work is required to study the interoperability between BIM and DT software.

The third major step consists of the evaluation of the impact of each suggested interventions on the basis of all significant parameters (budget, planning, etc.), including how these solutions will affect the conservations of the identified features of significance. There is a need for investigating, developing and implementing an evaluation model prototype in the DT environment.

The very next proposed research step is to develop a data model that allows the significance management considering objects relationships and temporal evolution. Then a data structuration prototype for the importation of heritage significance related information into HBIM process needs to be modelled. The digital workflow behind the proposed methodology has to be set up, tested and adjusted using existing tools and software, following AGILE's method principles and pointing out interoperability issues. All these planned developments will take place around a real test case that is under definition.

\section{ACKNOWLEDGMENTS}

This investigation is part of a Ph.D.'s research in the department of Art Archaeology and Heritage Research Unit, University of Liège, Belgium, and initiated in October 2018. The authors thank the reviewers for their constructive and accurate advices on this research. 


\section{REFERENCES}

Barazzetti, L., Banfi, F., Brumana, R., Oreni, D., Previtali, M., Roncoroni, F., 2015. HBIM and augmented information: Towards a wider user community of image and range-based reconstructions. Int. Arch. Photogramm. Remote Sens. Spatial Inf. Sci., XL-5/W7, 35-42. doi.org/10.5194/isprsarchives-XL-5W7-35-2015.

Brumana, R., Condoleo, P., Grimoldi, A., Previtali, M., 2019. Towards a semantic based hub platform of vaulted systems: Hbim meets a geodb. Int. Arch. Photogramm. Remote Sens. Spatial Inf. Sci., XLII-2/W11, 301-308. doi.org/10.5194/isprsArchives-XLII-2-W11-301-2019.

Brumana, R., Dellatorre, S., Oreni, D., Previtali, M., Cantini, L., Barazzetti, L., Franchi, A., Banfi, F., 2017. HBIM challenge among the paradigm of complexity, tools and preservation: The basilica Di collemaggio 8 years after the earthquake (L'aquila). Int. Arch. Photogramm. Remote Sens. Spatial Inf. Sci., XLII2/W5, 97-104. doi.org/10.5194/isprs-archives-XLII-2-W5-972017.

Cheng, H.M., Yang, W.B., Yen, Y.N., 2015. BIM applied in historical building documentation and refurbishing. Int. Arch. Photogramm. Remote Sens. Spatial Inf. Sci., XL-5/W7, 85-90. https://doi.org/10.5194/isprsarchives-XL-5-W7-85-2015.

Chiabrando, F., Lo Turco, M., Rinaudo, F., 2017. Modeling the decay in an hbim starting from $3 \mathrm{~d}$ point clouds. A followed approach for cultural heritage knowledge. Int. Arch. Photogramm. Remote Sens. Spatial Inf. Sci., XLII-2/W5, 605612. doi.org/10.5194/isprs-archives-XLII-2-W5-605-2017.

Dore, C., Murphy, M., 2012. Integration of Historic Building Information Modeling (HBIM) and 3D GIS for recording and managing cultural heritage sites. 18th International conference on Virtual Systems and Multimedia: "Virtual Systems in the Information Society", 2-5 September, 2012, Milan, Italy, 369376.

Elfadaly, A., Attia, W., Qelichi, M.M., Murgante, B., Lasaponara, R., 2018. Management of Cultural Heritage Sites Using Remote Sensing Indices and Spatial Analysis Techniques. Surveys in Geophysics (2018), 39(6), 1347-1377. doi.org/10.1007/s10712-018-9489-8.

Garagnani, S., Mingucci, R., Luciani, S.C., 2012. Collaborative design for existing architecture: the Building Information Modeling as a frontier for coordinated process. SIGraDi 2012, Proceedings of the 16th Iberoamerican Congress of Digital Graphics, 96-100.

Grieves, M., 2014. Digital Twin: Manufacturing Excellence through Virtual Factory Replication. White paper, Florida Insitute of Technology, 1-7.

Grieves, M., Vickers, J., 2016. Digital Twin: Mitigating Unpredictable, Undesirable Emergent Behavior in Complex Systems. In Kahlen, F.J., Flumerfelt, S., Alves, A., Transdisciplinary Perspectives on Complex Systems: New Findings and Approaches, 85-113. doi.org/10.1007/978-3-31938756-7_4.

HBIM Portal Development Team, 2016. HBIM - Smart Heritage Building Performance Measurement for Sustainability. http://www.hbim.org/ (28 june 2019).
ICOMOS, 1994. The Nara Document on Authenticity. Nara Conference on Authenticity, Nara, Japan. doi.org/10.1063/1.4748569.

Isikdag, U., Zlatanova, S., 2008. Towards Defining a Framework for Automatic Generation of Buildings in CityGML Using Building Information Models. 3D Geo-Information Sciences, Springer, Berlin, Heidelberg, 79-96. doi.org/10.1007/978-3540-87395-2_6.

Klein, L.J., Bermudez, S.A., Schrott, A.G., Tsukada, M., DionisiVici, P., Kargere, L., Marianno, F., Hamann, H.F., López, V., Leona, M., 2017. Wireless sensor platform for cultural heritage monitoring and modeling system. Sensors, 17, 1-21. doi.org/10.3390/s17091998.

Fredheim, L. H., \& Khalaf, M., 2016. The significance of values: heritage value typologies re-examined. International Journal of Heritage Studies, 22(6), pp. 466-481. doi.org/10.1080/13527258.2016.1171247.

Mesas-Carrascosa, F.J., Verdú Santano, D., Meroño de Larriva, J.E., Ortíz Cordero, R., Hidalgo Fernández, R.E., García-Ferrer, A., 2016. Monitoring heritage buildings with open source hardware sensors: A case study of the mosque-cathedral of Córdoba. Sensors, 16, 1-14.. doi.org/10.3390/s16101620.

Moraitou, E., Aliprantis, J., Caridakis, G., 2018. Semantic preventive conservation of cultural heritage collections. Proceedings of the Third International Workshop on Semantic Web for Cultural Heritage co-located with the 15th Extended Semantic Web Conference (ESWC 2018), CEUR-WS, 2094, 110.

Oreni, D., Brumana, R., Banfi, F., Bertola, L., Barazzetti, L., Cuca, B., Previtali, M., Roncoroni, F., 2014. Beyond Crude 3D Models: From Point Clouds to Historical Building Information Modeling via NURBS. Euro-Mediterranean Conference, Springer, Cham, 166-175. doi.org/10.1007/978-3-319-13695-0.

Oreni, D., Karimi, G., Barazzetti, L., 2017. Applying bim to built heritage with complex shapes: The ice house of filarete's ospedale maggiore in milan, Italy. Int. Arch. Photogramm. Remote Sens. Spatial Inf. Sci., XLII-2/W5, 553-560. doi.org/10.5194/isprs-archives-XLII-2-W5-553-2017.

PetroBIM Development Team, 2013. PetroBIM - Herramienta para la gestión del estudio y conservación del Patrimonio Histórico y su difusión. http://petrobim.com/ (28 June 2019).

Stephenson, J., 2008. The Cultural Values Model: An integrated approach to values in landscapes. Landscape and Urban $\begin{array}{lll}\text { Planning } & 84 & \text { (2008), }\end{array}$ doi.org/10.1016/j.landurbplan.2007.07.003.

Van Balen, K., 2017. Challenges that preventive conservation poses to the cultural heritage documentation field. Int. Arch. Photogramm. Remote Sens. Spatial Inf. Sci., XLII-2/W5, 713717. doi.org/10.5194/isprs-archives-XLII-2-W5-713-2017.

Van Balen, K., 2008. The Nara Grid: An Evaluation Scheme Based on the Nara Document on Authenticity. APT Bull., 39, issue 2-3, 39-46. 